\title{
The role of biopsychosocial factors in the rehabilitation process of individuals with a stroke
}

\author{
Marzena Kobylańska ${ }^{\mathrm{b}}$, Joanna Kowalska ${ }^{\mathrm{b}}$, Jolanta Neustein ${ }^{\mathrm{a}}$, Justyna Mazurek ${ }^{\mathrm{c}, *}$, \\ Bartosz Wójcik $^{\mathrm{a}}$, Małgorzata Bełza ${ }^{\mathrm{a}}$, Michał Cichosz ${ }^{\mathrm{a}}$ and Joanna Szczepańska-Gieracha ${ }^{\mathrm{b}}$ \\ ${ }^{a}$ Department of Neurological Rehabilitation, Wroclaw Centre for Rehabilitation and Sports Medicine, \\ Wroclaw, Poland \\ ${ }^{\mathrm{b}}$ Department of Physiotherapy, University School of Physical Education, Wroclaw, Poland \\ ${ }^{\mathrm{c}}$ Department and Division of Medical Rehabilitation, Wroclaw Medical University, Poland
}

Received 17 November 2017

Accepted 14 May 2018

\begin{abstract}
.
BACKGROUND: A large proportion of individuals with a stroke are unable to return to work, although figures vary greatly. Due to the very high cost of post-stroke care, both tangible and intangible, in the form of long-term social consequences, it seems extremely important to search for factors responsible for the low efficiency of the rehabilitation and recovery process, because this fact has direct influence on future employment. Such knowledge would enable physiotherapists to quickly identify those patients who are at risk of rehabilitation breakdown, in order to provide them with special care and include them in intensive therapeutic treatments.

OBJECTIVE: The aim of the study was to assess the efficacy of post-stroke rehabilitation, evaluated within the biopsychosocial aspect.

METHODS: The study consisted of 120 patients after first stroke, including 48 women and 72 men aged 58.0 ( \pm 8.6 ). The measure of the effects of physiotherapy in the present study was not only the improvement of the functional state (simple and complex activities of daily life, locomotive activities), but also the improvement of the mental state (mood and the sense of well-being, level of acceptance of illness, perceived self-efficacy) and the reduction of pain. The Mini-Mental State Examination, the Geriatric Depression Scale, the Generalized Self-Efficacy Scale, the Acceptance of Illness Scale, the Visual Analogue Scale, the Barthel Index, the Instrumental Activity of Daily Living and the Rivermead Mobility Index were used. All parameters were measured twice: on admission to the ward and after three weeks of physiotherapy. The characteristics of the study group were presented using descriptive statistics. The analysis of interdependence of the efficacy of physiotherapy used two non-parametric tests: the Mann-Whitney U test to compare two groups, and the Kruskal-Wallis ANOVA test to compare a greater number of groups. Correlations between characteristics with continuous distributions were assessed using Spearman's rank correlation coefficient $(\rho)$, and in case of categorical variables, Pearson's chi-squared $\left(\chi^{2}\right)$ correlation coefficient. Linear regression was used to determine the hierarchy of the influence of particular characteristics on the efficacy of physiotherapy.
\end{abstract}

RESULTS: Statistical analyzes show that patient's age, time since stroke, number of comorbidities, family care capacity, marital status of the patient and also a low level of acceptance of illness, depression symptoms and lack of a sense of self-efficacy were related with low efficacy of post-stroke rehabilitation

CONCLUSIONS: Comprehensive neurological rehabilitation, taking into account mental challenges and socio-economic circumstances of individuals with a stroke is essential in order to achieve high efficacy of physiotherapy. Important external factors may play a pivotal role in returning to work as well and should be taken into account during rehabilitation.

\footnotetext{
*Address for correspondence: Justyna Mazurek, PhD, MD, Department and Division of Medical Rehabilitation, ul. Borowska
}

213, Wroclaw, Poland. Tel.: +48 695180984; E-mail: justyna_ mazurek@poczta.onet.pl. 
Of interest should be to assess more biopsychological factors, such as acceptance of illness and a sense of self-efficacy referred to as barriers to return to work.

Keywords: Post-stroke rehabilitation, physiotherapy, occupational therapy, neurological rehabilitation, depression symptoms, return to work, younger adults, intervention, clinical practice

\section{Introduction}

In many European countries, the process of ageing of societies has been observed for years. Currently, the fastest ageing country in Europe is Poland. The total size of the Polish population aged 65 and over is predicted to grow from $15 \%$ in 2015 to $24 \%$ in 2035 [1]. It is estimated that the consequence of the above will be an increased incidence of diseases strongly associated with age, including stroke (cerebrovascular accident, CVA). At present, the incidence of CVA in Poland is comparable to other European countries (about 175/100,000 among men and 125/100,000 among women), but the post-stroke mortality and disability rates are significantly higher. A particularly high rate of death is observed in the early post-stroke stage. In Poland, the mortality rate within the first 14 days after a cerebrovascular accident is $13 \%$ (in other countries, the average is $9.6 \%$ ), and the total average stroke mortality per annum is $40 \%$ in men and $44 \%$ in women, whereby more patients die due to haemorrhagic $(60 \%)$ than ischaemic stroke [2,3]. Depending on the source, it is reported that $44-75 \%$ of stroke survivors remain dependent on external assistance (formal or informal care) (Rankin Scale $\geq 3$ ) at discharge from the hospital [2]. In 2013, over 330,000 individuals with a stroke in Poland were recognised as disabled [4].

A serious problem, reported by many studies, is an increasing incidence of stroke among young people, who are active both professionally and socially $[5,6]$. In Poland, only a small percentage of stroke survivors resume their professional activity. In fact, so few people return to work after a CVA that there is no reliable data regarding their actual number [7]. Data show that about $65 \%$ of patients affected by stroke before the 65th year of life fail to resume their professional activity, whereas another $14 \%$ rearrange their working hours [8]. At the same time, the literature emphasises that the loss of a job due to a CVA, followed by the loss of social status, leads to a deterioration in quality of life; these are significant factors increasing the risk of post-stroke depression [9-13].

Returning to work (RTW) is a primary rehabilitation goal. People who are employed report a better quality of life, less health service usage and better health status than non-employed people. More than $65 \%$ of working age adults with stroke fail to return to work [14]. In a systematic review examining the social consequences of stroke in working aged adults, Daniel et al. found that of the 8,810 stroke survivors working before stroke, only a mean $44 \%$ (range 0-100\%) returned to work [15]. Similar figures are reported in national prevalence surveys in Japan and Sweden, with higher proportions among younger stroke survivors who were working at onset $[16,17]$. Only about half of the individuals with a stroke were working the same number of hours a week one-year post-stroke as they had done prestroke, while the other half were working less or not at all. Several studies have found that effectiveness of physiotherapy measured with Barthel Index, Modified Rankin Scale, or Functional Independence Measure scores predict return to work post-stroke $[18,19]$. It is not only returning to work that presents a problem; ensuring people remain in work is also difficult. Stroke survivors may return prematurely and leave once the true impact of the stroke on their job is realized. Finally, it is known that physical, emotional, cognitive and psychological problems may result from stroke and affect work activities.

It would be of great value to determine more precisely which factors might predict poor efficacy of physiotherapy and related to this return to work poststroke. This would enable better information and more targeted care to be provided, in order to improve the support for individuals with a stroke in the process of reintegration into working life.

Knowledge about factors associated to the poor efficiency of the neurological rehabilitation after stroke would enable physiotherapists to quickly identify those patients who are at risk of rehabilitation breakdown, in order to provide them with special care and include them in intensive therapeutic treatments. The most valuable seem to be research projects that focus on the biopsychosocial determinants (which examine aspect of biology - e.g. age, gender, time since stroke, psychological components - e.g. depression, anxiety and social factors affecting an individual - e.g. material status, formal and informal care 
efficiency) of both the treatment and rehabilitation processes, as the factors linked to the efficacy of poststroke rehabilitation might be different, depending on the realities of the country, access to high-quality physiotherapy services as well as the socio-economic situation. Therefore, the aim of this project was to assess the efficacy of post-stroke rehabilitation carried out in one of the leading rehabilitation wards in Poland, evaluated from the biopsychosocial aspect.

\section{Materials and methods}

The study was carried out at the Department of Neurological Rehabilitation of the Wroclaw Centre for Rehabilitation and Sports Medicine. The participants were individuals with a stroke who had met the following inclusion criteria: a history of ischaemic or haemorrhagic stroke, the possibility to perform a full examination of cognitive functions, a satisfactory cognitive state (MMSE $\geq 19$ ) enabling further psychological tests, the possibility to perform physical fitness tests using methods defined in the project, and a functional state $\leq 85$ on the Barthel scale. The applied exclusion criteria were as follows: aphasia, a history of recurrent CVAs, the presence - at examination or in documentation - of intellectual disability, disorders of consciousness or other severe mental disorders, as well as addiction to drugs or other psychoactive substances. All participants consented in writing to take part in the study. The study population consisted of 120 individuals with a stroke, including 48 women and 72 men aged $58.0( \pm 8.6)$. The detailed characteristics of the study population, together with clinical and sociodemographic data, are shown in Table 1.

The mental state of the patients was evaluated with the Mini-Mental State Examination (MMSE), which is a widely used screening test of cognitive functions, including orientation to time and place, recall, attention, calculation, language and visuospatial skills. The maximum score a patient can attain is 30 points and a score of $30-27$ points indicates normal cognition [20, 21]. Also, the Geriatric Depression Scale (GDS-30) was used to assess the sense of well-being and mood of the patients. On this scale, a score above 10 points indicates depression, with higher scores pointing to a more severe condition $[22,23]$. Another measurement tool used was the 10-item Generalized Self-Efficacy Scale (GSES), which measures the individual's general sense of
Table 1

Baseline characteristics of the patients

\begin{tabular}{|c|c|}
\hline Baseline characteristics & Patients $(\%)(n=120)$ \\
\hline \multicolumn{2}{|l|}{ Age } \\
\hline Mean (SD) & $58.0(8.6)$ \\
\hline Range & $36-77$ \\
\hline \multicolumn{2}{|l|}{ Gender } \\
\hline Women & $48(40)$ \\
\hline Men & $72(60)$ \\
\hline \multicolumn{2}{|l|}{ Education } \\
\hline Primary and vocational & $52(43)$ \\
\hline Secondary & $45(38)$ \\
\hline Higher & $23(19)$ \\
\hline \multicolumn{2}{|l|}{ Occupation } \\
\hline Employed & $34(28)$ \\
\hline Retired & $53(44)$ \\
\hline Disability pensioners & $23(19)$ \\
\hline Unemployed & $10(8)$ \\
\hline \multicolumn{2}{|l|}{ Type of work } \\
\hline Physical & $71(59)$ \\
\hline Mental & $49(41)$ \\
\hline \multicolumn{2}{|l|}{ Marital status } \\
\hline Married & $70(58)$ \\
\hline Single people (unmarried) & $25(21)$ \\
\hline Widow(er) & $25(21)$ \\
\hline \multicolumn{2}{|l|}{ Place of residence } \\
\hline Town & $75(62)$ \\
\hline Village & $45(38)$ \\
\hline \multicolumn{2}{|l|}{ Family care } \\
\hline Full caring capacity & $56(47)$ \\
\hline Partial lack of care capacity & $37(31)$ \\
\hline Lack of care capacity & $27(23)$ \\
\hline \multicolumn{2}{|l|}{ Stroke type } \\
\hline Haemorrhagic & $91(76)$ \\
\hline Ischaemic & $29(24)$ \\
\hline \multicolumn{2}{|l|}{ Lesion location } \\
\hline Right hemispheric stroke & $75(62)$ \\
\hline Left hemispheric stroke & $45(38)$ \\
\hline \multicolumn{2}{|l|}{ Time since stroke (weeks) } \\
\hline Mean (SD) & $16.4(17.1)$ \\
\hline Range & $2-70$ \\
\hline \multicolumn{2}{|l|}{ Number of comorbidities } \\
\hline Mean (SD) & $1.6(1.5)$ \\
\hline Range & $0-5$ \\
\hline \multicolumn{2}{|l|}{ Body Mass Index (BMI) } \\
\hline Mean (SD) & $27.8(3.3)$ \\
\hline Normal & $24(20)$ \\
\hline Overweight & $71(59)$ \\
\hline Obese & $25(21)$ \\
\hline
\end{tabular}

perceived self-efficacy in coping with difficult situations and obstacles. The higher the score, the greater the perceived self-efficacy [24, 25]. The Acceptance of Illness Scale (AIS) consists of eight questions, describing the consequences of poor health and illness. The questions regard the limitations imposed by the illness, lack of self-sufficiency, the feeling of being dependent on others and reduced self-esteem. 
The higher the score, the higher the acceptance of the illness, manifested by a lack of negative emotions associated with it [26, 27]. Additionally, the Visual Analogue Scale (VAS) was used to assess pain intensity. Patients rate the intensity of their pain on a scale of $0-10$, where 0 corresponds to 'no pain' and 10 to 'worst possible pain' [28].

The functional state of the patients was measured with the Barthel Index (BI), which focuses on the basic activities of daily life, and the Instrumental Activity of Daily Living (IADL) Scale, which assesses more complex activities. The more points gained, the better the functional state of a patient [29-31]. Moreover, mobility and locomotion [32, 33] was assessed using the Rivermead Mobility Index (RMI). All the above parameters were measured twice: on admission of the patient to the ward and on the day of discharge, i.e. after three weeks of systematic physiotherapy.

The physiotherapy programme determining the frequency and duration of sessions (daily Monday to Friday for 140 minutes, and 50 minutes on Saturday) developed depending on the physical condition of a patient and included the following activities:

1. Individual exercises, taking into account neurological and functional deficits, were carried out using Proprioceptive Neuromuscular Facilitation (PNF) - 60 minutes daily, Monday to Friday.

2. Exercises using a biofeedback rehabilitation bike for simultaneous, active and passive rehabilitation of upper and lower limbs - 20 minutes daily, Monday to Saturday.

3. Gait re-education exercises (walking on flat and uneven surfaces, gait training treadmill and stairs) -30 minutes daily, Monday to Saturday.

4. Kinesitherapy combined with physical therapy and hydrotherapy. Depending on indications and contraindications, the programme used the following treatments:

- whirlpool therapy (performed alternately on the upper and lower limbs on consecutive days) - 20 minutes daily, Monday to Friday,

- scanning laser therapy (one treatment area at a time), dosage $2-4 \mathrm{~J} / \mathrm{cm}^{2}$, beam power of 400 $\mathrm{mW}-5-10$ minutes, Monday to Friday.

5. Physiotherapy was combined with occupational therapy in five-person groups - Monday to Friday up to 60 minutes, Saturday up to 30 minutes.

6. Psychological assistance, planned individually, in accordance with the physiotherapy schedule.

\section{Statistical methods}

The characteristics of the study group were presented using descriptive statistics. The empirical distribution of the studied characteristics, defining the effects of physiotherapy, deviated significantly from a normal distribution. Thus, the analysis of interdependence of the efficacy of physiotherapy used two non-parametric tests: the Mann-Whitney $\mathrm{U}$ test to compare two groups, and the KruskalWallis ANOVA test to compare a greater number of groups. Correlations between characteristics with continuous distributions were assessed using Spearman's rank correlation coefficient $(\rho)$, and in case of categorical variables, Pearson's chi-squared $\left(\chi^{2}\right)$ correlation coefficient. Also, linear regression was used to determine the hierarchy of the influence of particular characteristics on the efficacy of physiotherapy. Statistical tests were performed at a significance level of 0.05 .

\section{Results}

On admission to the neurological rehabilitation ward, the mean MMSE score among the study population was $28.0( \pm 2.3)$, with $83.3 \%$ of the study subjects showing no cognitive impairment (MMSE 27-30), 10\% showing cognitive impairment without dementia (MMSE 24-26), and 6.3\% showing mild dementia (MMSE <24). The mean GDS score was $8.1( \pm 5.9)$, and in $62.5 \%$ of the study population the mood was normal (GDS 0-10), while $37.3 \%$ showed signs of depression (GDS > 10). Mean scores of the AIS, the GSES and the VAS were $22.3( \pm 9.2), 27.9$ $( \pm 9.4)$ and $1.0( \pm 2.3)$, respectively. As far as the physical fitness tests are concerned, the mean score of the BI was $56.4( \pm 16.0)$, the RMI was $7.1( \pm 2.3)$ and the IADL was $17.2( \pm 4.1)$. The efficacy of physiotherapy was assessed by comparing the initial and final values of all the studied parameters. Patients whose condition showed no improvement were also identified. The programme of physiotherapy proved to be the least effective within the VAS, the GSES and the GDS scales, and the most effective within the BI and the RMI scales (Fig. 1).

The efficacy of physiotherapy in terms of functional ability was assessed with three different scales: the BI, the IADL and the RMI. All three parameters were highly correlated, especially the BI and the RMI. Improvements in mobility and independence in daily activities (BI and RMI) were significantly positively 


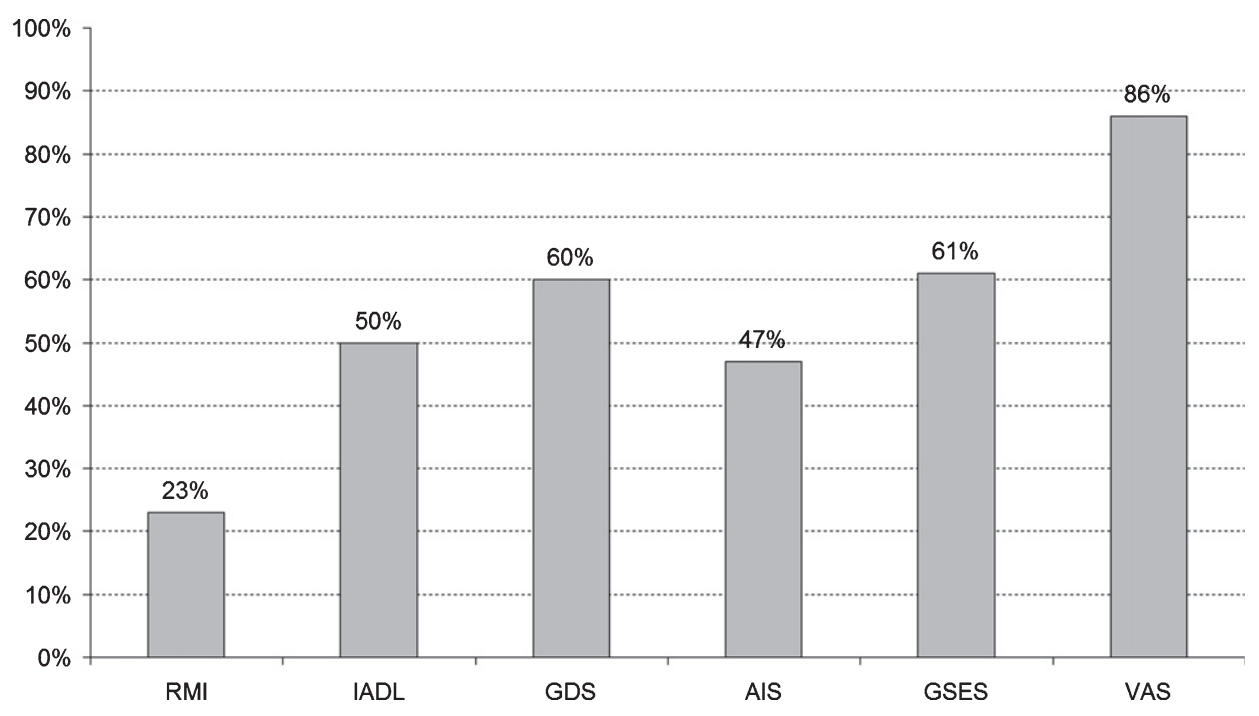

Fig. 1. The percentage of patients without improvement after three weeks of physiotherapy.

correlated with mood improvement (GDS), acceptance of illness (AIS) and perceived self-efficacy (GSES), but there was no correlation with the change in pain intensity (VAS). The efficacy of the treatments measured with the IADL scale correlated significantly only with the AIS. The correlation analysis of the initial values of the MMSE, the GDS, the AIS and the GSES with the improved values after physiotherapy showed a significant correlation between the GDS and the efficacy of therapy evaluated with the BI and the RMI, and a significantly positive correlation between the initial values of the AIS and the BI, the RMI, the IADL, the GDS as well as the GSES. Furthermore, higher initial GSES values contributed favourably to the efficacy of therapy in all the studied parameters, except for the VAS (Table 2).

\subsection{The dependence of the effects of physiotherapy on biopsychosocial factors}

The average age of patients who showed improvement was higher than the average age of patients who showed no improvement in any of the studied parameters, except for the VAS. However, a statistically significant dependence between the improvement of a patient's state after physiotherapy and the patient's age was observed only with regard to the RMI and the GSES ( $p=0.005$ and $p=-0.026)$. Taking into account the mean values of the analysed characteristics, greater improvement was observed in ischaemic individuals with a stroke. However, statistically
Table 2

Correlations between the efficacy of physiotherapy and the initial values of the MMSE, the GDS, the AIS and the GSES

\begin{tabular}{lrrrr}
\hline $\begin{array}{l}\text { Parameter } \\
\text { Scale) }\end{array}$ & \multicolumn{4}{c}{$\begin{array}{c}\text { Correlations with initial values } \\
\text { (rho-Spearman) }\end{array}$} \\
\cline { 2 - 5 } & MMSE & GDS & AIS & GSES \\
\hline BI & 0.137 & $\mathbf{- 0 . 3 8 3}$ & $\mathbf{0 . 3 2 6}$ & $\mathbf{0 . 5 0 9}$ \\
Rivermead & 0.067 & $\mathbf{- 0 . 3 3 2}$ & $\mathbf{0 . 3 8 0}$ & $\mathbf{0 . 4 2 6}$ \\
IADL & -0.043 & -0.160 & $\mathbf{0 . 2 0 4}$ & $\mathbf{0 . 3 1 8}$ \\
GDS & 0.114 & 0.100 & $\mathbf{0 . 2 0 5}$ & $\mathbf{0 . 2 0 7}$ \\
AIS & -0.046 & -0.152 & 0.085 & $\mathbf{0 . 3 2 2}$ \\
GSES & 0.173 & -0.128 & $\mathbf{0 . 1 9 6}$ & 0.074 \\
VAS & -0.093 & -0.019 & -0.113 & -0.038 \\
\hline
\end{tabular}

significant differences were detected with respect to the BI, the GDS and the AIS (Table 3).

No significant dependence was detected between the location of the stroke (left or right hemisphere) and the effects of physiotherapy. However, a statistically significant, negative correlation was observed between the time since stroke and the commencement of rehabilitation. This dependence was visible in the BI, RMI and IADL results ( $p=0.0003, p=0.0019$ and $p<0.0001$, respectively). Post hoc comparison of mean values using Fisher's Least Significant Difference (LSD) test demonstrated that physiotherapy was definitely the least effective in cases where patients were admitted to the rehabilitation ward later than 16 weeks after stroke.

The number of comorbidities was significantly correlated with the change in GDS and VAS values after physiotherapy ( $p=0.0435$ and $p=0.0292$ ). The greater the number of comorbidities, the smaller 
Table 3

The efficacy of physiotherapy depending on stroke type (U Mann-Whitney test)

\begin{tabular}{|c|c|c|c|c|c|c|c|c|c|c|}
\hline \multirow[t]{2}{*}{ Parameter (Scale) } & \multirow[t]{2}{*}{ Stroke type } & \multicolumn{2}{|c|}{ Pre-therapy } & \multicolumn{2}{|c|}{ Post-therapy } & \multirow[t]{2}{*}{ Mean change } & \multicolumn{2}{|c|}{$I C$} & \multirow[t]{2}{*}{$U$} & \multirow[t]{2}{*}{$p$} \\
\hline & & Mean & SD & Mean & SD & & $-95 \%$ & $+95 \%$ & & \\
\hline \multirow[t]{2}{*}{ BI } & Ischaemic & 56.15 & 16.52 & 71.43 & 14.72 & 15.27 & 12.70 & 17.96 & 931.0 & 0.019 \\
\hline & Haemorrhagic & 57.07 & 14.30 & 66.21 & 12.86 & 9.14 & 9.14 & 5.17 & & \\
\hline \multirow[t]{2}{*}{ RMI } & Ischaemic & 7.15 & 2.23 & 9.00 & 1.96 & 1.85 & 1.65 & 2.26 & 994.5 & 0.095 \\
\hline & Haemorrhagic & 6.93 & 2.46 & 8.31 & 2.00 & 1.38 & 1.41 & 0.77 & & \\
\hline \multirow[t]{2}{*}{ IADL } & Ischaemic & 17.33 & 4.31 & 18.87 & 3.72 & 1.54 & 1.17 & 1.91 & 1068.0 & 0.126 \\
\hline & Haemorrhagic & 16.66 & 3.55 & 17.55 & 3.19 & 0.90 & 0.97 & 0.33 & & \\
\hline \multirow[t]{2}{*}{$\overline{\text { GDS }}$} & Ischaemic & 7.93 & 6.30 & 7.49 & 6.53 & -0.44 & 0.88 & 1.65 & 967.0 & 0.025 \\
\hline & Haemorrhagic & 8.55 & 4.66 & 9.76 & 5.53 & 1.21 & 0.45 & 0.06 & & \\
\hline \multirow[t]{2}{*}{ AIS } & Ischaemic & 23.01 & 9.05 & 25.36 & 9.95 & 2.35 & 2.08 & 3.64 & 891.0 & 0.014 \\
\hline & Haemorrhagic & 21.17 & 9.56 & 21.07 & 10.04 & -0.10 & 1.03 & 0.29 & & \\
\hline \multirow[t]{2}{*}{$\overline{\text { GSES }}$} & Ischaemic & 28.97 & 9.26 & 30.40 & 9.61 & 1.43 & 1.25 & 2.60 & 1187.5 & 0.186 \\
\hline & Haemorrhagic & 24.38 & 9.30 & 24.72 & 10.47 & 0.34 & 1.07 & 0.30 & & \\
\hline \multirow[t]{2}{*}{ VAS } & Ischaemic & 0.96 & 2.19 & 0.68 & 1.68 & -0.27 & 0.13 & 0.42 & 1261.0 & 0.826 \\
\hline & Haemorrhagic & 1.14 & 2.67 & 0.90 & 2.11 & -0.24 & 0.24 & -0.06 & & \\
\hline
\end{tabular}

Table 4

Efficacy of rehabilitation depending on time elapsed since stroke

\begin{tabular}{lcccccc}
\hline $\begin{array}{l}\text { Parameter } \\
\text { Scale })\end{array}$ & $\begin{array}{c}\text { Time since } \\
\text { stroke [weeks] }\end{array}$ & $n$ & $\begin{array}{c}\text { Mean } \\
\text { improvement }\end{array}$ & \multicolumn{3}{c}{ Post hoc comparisons (LSD) } \\
\cline { 5 - 7 } BI & $\leq 4\{\mathrm{~A}\}$ & 43 & 15.47 & 0.3071 & 0.0004 & 0.0062 \\
& $5-16\{\mathrm{~B}\}$ & 36 & 18.19 & & & \\
\hline RMI & $>16\{\mathrm{C}\}$ & 41 & 8.29 & & & 0.0128 \\
& $\leq 4\{\mathrm{~A}\}$ & 43 & 1.91 & 0.1559 & $<0.0001$ & \\
& $5-16\{\mathrm{~B}\}$ & 36 & 2.53 & & & 0.0001 \\
\hline IADL & $>16\{\mathrm{C}\}$ & 41 & 1.12 & & & \\
& $\leq 4\{\mathrm{~A}\}$ & 43 & 1.95 & 0.6360 & 0.0008 & \\
& $5-16\{\mathrm{~B}\}$ & 36 & 1.78 & & & \\
\hline
\end{tabular}

the improvement. The patient's gender, BMI and the place of residence (town/village) showed no correlations with the efficacy of physiotherapy in any of the analysed parameters. The place of admission (whether admitted from home or hospital) was found to correlate with physiotherapy efficacy measured with the IADL. A greater improvement in functional state was recorded in patients admitted to the rehabilitation ward directly from the hospital $(p=0.017)$. Where education is concerned, the following dependence was found: patients with primary and vocational education demonstrated a significantly greater improvement in mood (reduction of depression) compared to patients with secondary and higher education $(p=0.004)$. We found a very strong dependence between the efficacy of physiotherapy and the patient's marital status. In all the studied parameters, except for the VAS, therapy was far more effective in married participants (Table 5).

Moreover, family care capacity (FCC) was also tightly associated with the efficacy of physiotherapy.
Patients whose families demonstrated full care capacity showed the greatest improvement in physiotherapy measured with the IADL.

To determine the hierarchy of the influence of the abovementioned characteristics on the effects of physiotherapy - since the analysis considered seven parameters (from BI to VAS) - a collective measure of efficacy was established by summing the number of improvement cases related to each of these parameters. Thus, the resultant measure assumed, in theory, values from 0 (no improvement) to 7 (improvement in all the parameters). Figure 2 presents the absolute values of standardised linear regression coefficients. Standardisation enables a comparison of the values of these coefficients, as they are independent of the units in which the individual characteristics are expressed. The analysis used absolute values due to the dependence between the sign of the coefficient and the coding sequence for categorical variables. It was assumed that the higher the value of a coefficient, the stronger the influence 
Table 5

Dependence between the effects of physiotherapy and marital status of patients (U Mann-Whitney test)

\begin{tabular}{llccccc}
\hline $\begin{array}{l}\text { Parameter } \\
\text { (Scale) }\end{array}$ & Marital status & $\begin{array}{c}\text { Mean post-physiotherapy } \\
\text { improvement }\end{array}$ & \multicolumn{2}{c}{ IC } & U & $p$ \\
\cline { 3 - 5 } BI & Married & 17.36 & 14.43 & 20.28 & 1020.0 & $\mathbf{0 . 0 0 0 1}$ \\
& Widow(er) or single & 8.90 & 5.80 & 12.00 & & \\
\hline RMI & Married & 2.09 & 1.74 & 2.43 & 1266.5 & $\mathbf{0 . 0 0 8 3}$ \\
& Widow(er) or single & 1.46 & 1.02 & 1.90 & & \\
\hline IADL & Married & 1.73 & 1.28 & 2.18 & 1326.0 & $\mathbf{0 . 0 1 5 6}$ \\
& Widow(er) or single & 0.94 & 0.53 & 1.35 & & \\
\hline GDS & Married & 1.41 & 0.94 & 1.89 & 1310.5 & $\mathbf{0 . 0 0 8 2}$ \\
& Widow(er) or single & 0.58 & 0.27 & 0.89 & & \\
\hline AIS & Married & 2.84 & 2.00 & 3.69 & 1298.5 & $\mathbf{0 . 0 1 1 2}$ \\
& Widow(er) or single & 1.82 & 0.87 & 2.77 & & \\
\hline GSES & Married & 2.20 & 1.42 & 2.98 & 1332.5 & $\mathbf{0 . 0 1 1 6}$ \\
& Widow(er) or single & 1.04 & 0.33 & 1.75 & & \\
\hline VAS & Married & 0.30 & 0.12 & 0.48 & 1683.0 & 0.5591 \\
& Widow(er) or single & 0.22 & 0.04 & 0.40 & & \\
& & & & & &
\end{tabular}

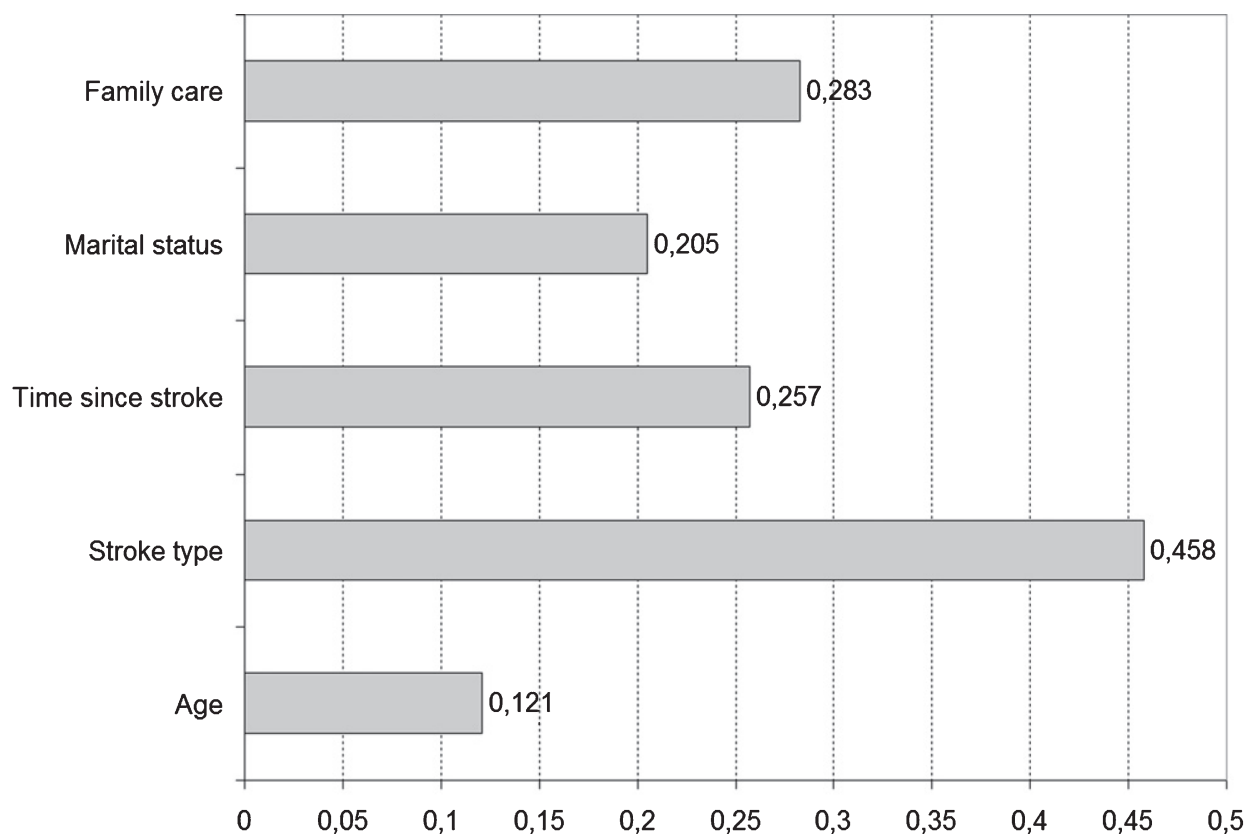

Fig. 2. Absolute values of the standardised regression coefficients: efficacy of physiotherapy vs. the characteristics that affect it.

of the related characteristic on physiotherapy efficacy. This study found that the following factors had the strongest impact on the effects of therapy: type of stroke, FCC, time since stroke and marital status.

In the next stage, patients who showed little improvement after therapy were identified (where value of the described measure was $\leq 2: 44$ patients, i.e. $37 \%$ of the studied population). The juxtaposition of the number of low-efficacy cases and the values of characteristics affecting physiotherapy efficacy (Table 7) confirm the conclusions drawn from the regression analysis.

The final part of the statistical analysis also presents the values of the characteristics most strongly associated with poor efficacy of post-stroke rehabilitation (Table 8).

\section{Discussion}

Despite continuous advancements in medicine, year by year, most countries see a growing number 
Table 6

Dependence between effects of physiotherapy and family care capacity (Kruskal-Wallis ANOVA, post hoc test: LSD)

\begin{tabular}{|c|c|c|c|c|c|c|c|c|c|c|}
\hline \multirow{2}{*}{$\begin{array}{l}\text { Parameter } \\
\text { (Scale) }\end{array}$} & \multirow{2}{*}{$\begin{array}{l}\text { Family care } \\
\text { capacity }\end{array}$} & \multirow[t]{2}{*}{ Code } & \multirow{2}{*}{$\begin{array}{l}\text { Mean post-physiotherapy } \\
\text { improvement }\end{array}$} & \multicolumn{2}{|c|}{ IC } & \multirow[t]{2}{*}{$\mathrm{H}(2, \mathrm{~N}=120)$} & \multirow[t]{2}{*}{$p$} & \multicolumn{3}{|c|}{$p$ (post hoc) } \\
\hline & & & & $-95 \%$ & $+95 \%$ & & & A-B & $\mathrm{A}-\mathrm{C}$ & $\mathrm{B}-\mathrm{C}$ \\
\hline \multirow[t]{3}{*}{$\mathrm{BI}$} & Full & $\mathrm{A}$ & 19.02 & 15.81 & 22.22 & 22.77 & $<0.0001$ & 0.0058 & $<0.0001$ & 0.1168 \\
\hline & Partial & $\mathrm{B}$ & 11.22 & 7.20 & 15.23 & & & & & \\
\hline & None & $\mathrm{C}$ & 6.67 & 3.15 & 10.18 & & & & & \\
\hline \multirow[t]{3}{*}{ RMI } & Full & A & 2.07 & 1.72 & 2.42 & 9.98 & 0.0068 & 0.8912 & 0.0063 & 0.1451 \\
\hline & Partial & B & 1.97 & 1.38 & 2.57 & & & & & \\
\hline & None & $\mathrm{C}$ & 1.11 & 0.58 & 1.64 & & & & & \\
\hline \multirow[t]{3}{*}{ IADL } & Full & A & 1.84 & 1.34 & 2.34 & 8.29 & 0.0158 & 0.1792 & 0.0413 & 0.2756 \\
\hline & Partial & B & 1.22 & 0.63 & 1.80 & & & & & \\
\hline & None & $\mathrm{C}$ & 0.74 & 0.24 & 1.24 & & & & & \\
\hline \multirow[t]{3}{*}{ GDS } & Full & A & 1.21 & 0.74 & 1.69 & 5.14 & 0.0767 & 0.6852 & 0.0549 & 0.1491 \\
\hline & Partial & $\mathrm{B}$ & 1.30 & 0.65 & 1.94 & & & & & \\
\hline & None & $\mathrm{C}$ & 0.44 & 0,04 & 0.85 & & & & & \\
\hline \multirow[t]{3}{*}{ AIS } & Full & A & 3.70 & 2,60 & 4.79 & 18.32 & 0.0001 & 0.0432 & 0.0003 & 0.3607 \\
\hline & Partial & $\mathrm{B}$ & 1.70 & 0,81 & 2.59 & & & & & \\
\hline & None & $\mathrm{C}$ & 0.74 & 0,02 & 1.46 & & & & & \\
\hline \multirow[t]{3}{*}{ GSES } & Full & $\mathrm{A}$ & 1.88 & 1,18 & 2.57 & 6.75 & 0.0343 & 0.9540 & 0.0776 & 0.1538 \\
\hline & Partial & B & 1.84 & 0,70 & 2.98 & & & & & \\
\hline & None & $\mathrm{C}$ & 1.22 & $-0,08$ & 2.53 & & & & & \\
\hline \multirow[t]{3}{*}{$\overline{\text { VAS }}$} & Full & A & 0.32 & 0,12 & 0.52 & 1.45 & 0.4851 & 0.8657 & 0.6024 & 0.8922 \\
\hline & Partial & B & 0.24 & 0,02 & 0.47 & & & & & \\
\hline & None & $\mathrm{C}$ & 0.19 & $-0,08$ & 0.45 & & & & & \\
\hline
\end{tabular}

Table 7

Efficacy of physiotherapy depending on the studied characteristic (chi-square test)

\begin{tabular}{|c|c|c|c|c|c|c|}
\hline \multirow[t]{2}{*}{ Characteristics } & \multirow[t]{2}{*}{ Categories } & \multicolumn{2}{|c|}{ Low efficacy } & \multicolumn{2}{|c|}{ Other cases } & \multirow[t]{2}{*}{$p$} \\
\hline & & $n$ & $\%$ & $n$ & $\%$ & \\
\hline \multirow[t]{3}{*}{ Age (years) } & $\leq 55$ & 26 & 22 & 19 & 16 & 0.0009 \\
\hline & $5 \overline{6}-60$ & 7 & 6 & 18 & 15 & \\
\hline & $>60$ & 11 & 9 & 39 & 33 & \\
\hline \multirow[t]{3}{*}{ Time since stroke (weeks) } & $\leq 4$ & 16 & 13 & 27 & 23 & 0.1520 \\
\hline & $5-20$ & 9 & 8 & 27 & 23 & \\
\hline & $>20$ & 19 & 16 & 22 & 18 & \\
\hline \multirow[t]{2}{*}{ Stroke } & Haemorrhagic & 26 & 22 & 65 & 54 & 0.0011 \\
\hline & Ischaemic & 18 & 15 & 11 & 9 & \\
\hline \multirow[t]{2}{*}{ Admitted from Hospital } & Home & 24 & 20 & 46 & 38 & 0.6158 \\
\hline & 19 & 16 & 30 & 25 & & \\
\hline \multirow[t]{2}{*}{ Marital status } & Married & 16 & 13 & 54 & 45 & 0.0002 \\
\hline & Widow(er) or single & 28 & 23 & 22 & 18 & \\
\hline \multirow[t]{3}{*}{$\overline{\mathrm{FCC}}$} & Full & 11 & 9 & 45 & 38 & 0.0001 \\
\hline & Partial & 15 & 13 & 22 & 18 & \\
\hline & None & 18 & 15 & 9 & 8 & \\
\hline
\end{tabular}

of elderly people who suffer a first-ever or recurrent stroke [3], which is primarily due to the ageing of societies. Unfortunately, stroke also increasingly affects younger people, who are professionally and socially active. Due to the varied etiopathogenesis and diversity of symptoms of the CVA, post-stroke rehabilitation may only be effective with the collaboration of an interdisciplinary therapeutic team.
Knowledge of the factors responsible for the poor efficacy of rehabilitation may facilitate an individual approach for each patient, and enable the prompt set-up of the necessary therapeutic support for those whose rehabilitation process might be at risk of failure. Therefore, research projects expanding the present knowledge of factors associated with ineffective post-stroke rehabilitation are still in high demand. 
Table 8

Values/categories of biologic and sociodemographic characteristics related to the lowest projected efficacy of physiotherapy

\begin{tabular}{ll}
\hline Characteristic & Value/category \\
\hline Age & Under 55 \\
Diagnosis & Hemorrhagic stroke \\
Time since stroke & Over 16 weeks \\
Admitted from & Home \\
Marital status & Single/widow(er) \\
FCC & Low or none \\
\hline
\end{tabular}

It seems appropriate for the predictive model to be based on simple factors that can be assessed as soon as the patient is admitted to the rehabilitation ward, and such was the aim of this research project.

Individuals with a stroke should be given the best possible support in the process of reintegration into working life. Black and Frost call for early health based interventions to prevent job loss (by keeping the door to an existing employer open) and recognise that supporting those who have the capacity to work is an important role for health care professionalism [34]. Authors of other studies underline, that many receive no support at all while some are able to access support from within the workplace, but few are able to obtain stroke-specific expertise to guide them. Advice and support from clinicians specific to the individual with stroke is welcomed by employers, but there are questions as to how such support could be funded and integrated within existing service provision which further studies need to address. There appears to be a complex array of relationships that ideally should align to orchestrate a successful return to work following stroke. The knowledge about the most important factors related to low efficacy of post-stroke rehabilitation is one of them [35]. In other studies the most common inhibiting factors for not returning to work include upper limb dysfunction, walking difficulties [36], fatigue, unsatisfactory rehabilitation [37], cognitive deficits and depression, low self-esteem, fear of social stigma, unsupportive work environment, speech impediment, and motor impairments [38]. Kemp and co-authors underline that in regards to the factors predicting return to work, global cognitive functioning and depressive symptoms were significantly associated with return to work one-year post-stroke, but only impaired global cognitive functioning appeared to be a statistically significant independent predictor of return to work [39].
In our study, the condition of the patients was evaluated in various aspects (biological, psychological and social) to capture as many dependencies as possible and, as a consequence, to be able to understand the underlying reasons for poorly effective rehabilitation. In many studies, when evaluating the effects of post-stroke rehabilitation, researchers focus their attention mainly on the assessment of motor and functional ability deficits [40, 41]. In our opinion, to properly evaluate the effects of treatment, one must also take into account the mental state of the patient. The literature provides considerable evidence that the presence of cognitive disorders or depression may greatly impair the process of rehabilitation and affect its final outcome [42-44]. And here the question arises, what is meant by 'the final outcome of rehabilitation'? Does this concern the moment of discharge from a rehabilitation ward? Or, should the measure of the effects of rehabilitation rather be the patient's return to their pre-stroke environment? Or, should it be the patient's determination to recover their functional ability and resume the social roles that were lost or limited due to their illness? And finally, why should the rehabilitation outcome not be measured in terms of acceptance by the patient of the limitations imposed by the illness, while maintaining their sense of self-esteem, self-efficacy and agency?

If the recovery of locomotive functions is to be the measure of success, the literature claims that a better outcome of physiotherapy is to be expected in young, male patients and patients with no cognitive disorders. We also know that, in terms of functional state, better improvement is achieved by patients who commenced the rehabilitation process within seven days of the cerebrovascular accident $[45,46]$. If the measure of success is to be the discharge of the patient to their own home, not a nursing facility, then according to the literature, it is more likely to happen in cases of patients characterised by a younger age [47, 48], a better functional $[47,49]$ and cognitive state on admission to [50], and/or discharge from the rehabilitation ward [51], lack of depression symptoms [47, 50], a smaller ischaemic area and one-sided paresis [40], being married [47] and living with a partner or family member before the stroke [49]. There is no agreement as to whether a high level of physical activity prior to stroke has any significant impact on the functional state of stroke survivors and whether it increases the chances of the patient returning home $[51,52]$. 
In Polish conditions, evaluating the efficacy of physiotherapy based on the discharge destination (home/care facility) seems misleading, as most patients are discharged home due to a dramatic shortage of places in long-term care facilities. Financial deficits in the healthcare system have resulted in the so-called familisation of care, where the burden of caring for a disabled person is shifted to the patient's family [53]. Moreover, certain cultural factors, the prevailing family model and the strong influence of the Catholic Church result in a situation where many Polish familial caregivers never even consider placing a relative in institutionalised care, for fear of social contempt and their own guilty conscience. As a consequence, Polish data in this respect should not be compared with findings from other countries.

The measure of the effects of physiotherapy in the present study was not only an improvement in the functional state (simple and complex activities of daily life, locomotive activities), but also an improvement in the mental state (mood and the sense of well-being, level of acceptance of illness, perceived self-efficacy) and the reduction of pain. The obtained data demonstrate that a patient's mental condition on admission is a strong predictor of the success of rehabilitation regarding both the functional and mental state. This is very important, as mood disorders, low level of acceptance of one's illness and low perceived self-efficacy are all easy to detect with simple screening tests at an early stage of the rehabilitation process. At the same time, all the above characteristics may be modified with therapeutic treatments [54]. The findings of our study are a relevant addition to the current state of knowledge, as many authors have already confirmed the association between mood disorders and the effects of physiotherapy [42, 43, 55]. However, to date, no study has examined how acceptance of the illness and perceived self-efficacy affect the rehabilitation process. Such knowledge is essential during psychological therapy conducted in the course of post-stroke rehabilitation, as it indicates the areas important for the success of rehabilitation and provides strategic directions for therapy. The present study did not confirm the influence of cognitive disorders on the course and final effects of rehabilitation, but it must be noted that one of the exclusion criteria was the presence of severe cognitive deficits (MMSE < 19), and only disorders with this level of severity have a negative impact on rehabilitation effects. Therefore, the obtained results confirm the existing scientific knowledge, rather than contradict it.
The remaining findings, related to clinical and sociodemographic factors, also mostly confirm the current state of knowledge. The literature contains the findings of other authors showing that a longer period from diagnosis to the start of rehabilitation and a greater number of comorbidities reduce the chance of success of physiotherapy treatment [56]. Our study also confirmed a strong correlation between the effects of rehabilitation and the patient's marital status as well as the care capacity of the family. It is a result worth noting. The literature tells us that patients living with a spouse/partner or family prior to stroke have a better chance of being discharged home (and not to a care facility) after the CVA [46, $48,56,57]$, which seems rather obvious and comes as no surprise. In our experiment, however, although the observation was carried out for only three weeks (during the patients' stay at the neurological rehabilitation ward), a strong correlation was discovered between a patient's life circumstances and the effects of rehabilitation, which indicates the importance of both the psyche and broadly understood social factors in post-stroke rehabilitation.

The most surprising finding of this project concerns the correlation between the effects of rehabilitation and the age of the patient. Our research indicates that age less than 55 years is a factor related to poor efficacy of rehabilitation, which is in conflict with the current state of knowledge. In our opinion, this results from the assumptions of the project, where the adopted measure of efficacy of rehabilitation concerned an improvement in the mental state of the patient as well as their functional state. It appears that younger, socially and professionally active people, who prior to the stroke were the 'head of the family', experience a deeper crisis and, as a consequence, need more time than older people to regain their mental equilibrium. In the described study, the initial and final measurements were taken only three weeks apart, and this was the basis for the conclusion that younger age was related to lower efficacy of rehabilitation. This result provides an important therapeutic direction, namely that in the process of post-stroke rehabilitation, special attention should be paid to younger patients, who at the time of treatment may also be struggling with a serious mental crisis. Provision of immediate psychological assistance in such cases may significantly improve the final rehabilitation outcome. Therefore, every effort should be made to ensure the quick identification of patients who may be at risk of rehabilitation and returning to work failure, taking into account their mental 
state (intensification of depressive symptoms, level of acceptance of illness, perceived self-efficacy), age and personal life situation, with a view to increasing their chance of successful rehabilitation and to make the best possible use of the time spent in the rehabilitation ward [13, 58]. Considering the epidemiology of stroke, the study group is relatively small. A larger study needs to be conducted to validate the results reported in this article. The small study population also limits the generalisability of the results. The study was limited to the individuals with a stroke of one large centre, which may not fully reflect the efficacy of neurological rehabilitation in other regions or cities in Poland, particularly in smaller towns. The comparison of our findings with those from other authors was limited due to differences in the selection of the study group.

\section{Conclusions}

1 Poor efficacy of physiotherapy is related to the presence of depression symptoms, a low level of acceptance of illness and a lack of a sense of selfefficacy in the rehabilitation process.

2 Factors related to low efficacy of post-stroke rehabilitation are: age, time since stroke, number of comorbidities, FCC and marital status of the patient.

3 Comprehensive neurological rehabilitation, taking into account the mental health problems and socio-economic circumstances of individuals with a stroke, is essential in order to achieve high efficacy of physiotherapy.

4 We therefore suggest that all individuals with a stroke of working age should be offered a psychological and cognitive screening, or a more comprehensive neuropsychological assessment to gain more insight into emotional and cognitive strengths and weaknesses, and if applicable should start comprehensive therapy and rehabilitation, to influence the outcome.

\section{Conflict of interest}

The authors report no conflicts of interest.

\section{References}

[1] GUS. Sytuacja demograficzna osób starszych i konsekwencje starzenia się ludności Polski w świetle prognozy na lata 2014-2050. Warszawa. 2014.
[2] Strzelecki Z, Szymborski J (red.). Zachorowalność i umieralność na choroby układu krążenia a sytuacja demograficzna Polski. Rządowa Rada Ludnościowa, Warszawa. 2015.

[3] Béjot Y, Bailly H, Durier J, Giroud M. Epidemiology of stroke in Europe and trends for the 21st century. Presse Med. 2016;45(12):391-8; doi: 10.1016/j.lpm.2016.10.003

[4] Kleinrok A, Płaczkiewicz D, Stefańczyk P, et al. Wpływ wybranych czynników socjodemograficznych i klinicznych na stopień niepełnosprawności pacjentów hospitalizowanych z powodu udaru mózgu. Przegl Med Uniw Rzesz. 2013;2:151-63.

[5] Yamamoto FI. Ischemic stroke in young adults: An overview of etiological aspects. Arq Neuropsiquiatr. 2012;70(6):4626.

[6] Anticoli S, Bravi MC, Pezzella FR. Stroke in the Young Adults: 6-Year Case Series of Community Hospital Stroke Unit. Open J Emerg Med. 2015;3:23-7; doi: 10.4236/ojem.2015.33005.

[7] Berny W, Zub W, Jarmundowicz W, et al. Professional and social functioning of patients after cerebral insult. Annales Universitatis Mariae Curie-Skłodowska LublinPolonia. 2005;LX, SUPPL.XVI, 24:102-5.

[8] Kersten P, Low J, Ashburn A, et al. The unmet needs of young people who have had a stroke: Results of a national UK survey. Disabil Rehabil. 2002;24:860-6.

[9] Wichowicz H. Czynniki ryzyka depresji poudarowej. Udar mózgu. 2008;10(2):91-5.

[10] Vestling M, Ramel E, Iwarsson S. Quality of life after stroke: Well-being, life satisfaction and subjective aspect of work. Scand J Occup Ther. 2005; 12:89-95.

[11] Ziółkowska-Kochan M, Pracka D. Depresja po udarze mózgu. Psychiatr Prakt Ogólnolek. 2003;3:203-8.

[12] Treger I, Shames J, Giaquinto S, et al. Return to work in stroke patients. Disabil Rehabil. 2007;29(17):1397-403.

[13] Gilworth G, Phil M, Sansam KAJ, et al. Personal experiences of returning to work following stroke: An exploratory study. Work. 2009;34:95-103.

[14] Coole C, Radford K, Grant M, Terry J. Returning to work after stroke: Perspectives of employer stakeholders, a qualitative study. J Occup Rehabil. 2013;23(3):406-18. doi: 10.1007/s10926-012-9401-1.

[15] Daniel K, Wolfe CD, Busch MA, McKevitt C. What are the social consequences of stroke for working-aged adults? A Systematic Review. Stroke. 2009;40(6):e431-e440. doi: 10.1161/STROKEAHA.108.534487

[16] Saeki S, Toyonaga T. Determinants of early return to work after first stroke in Japan. J Rehabil Med. 2010;42(3): 254-8.

[17] Lindström B, Röding J, Sundelin G. Positive attitudes and preserved high level of motor performance are important factors for return to work in younger persons after stroke: A national survey. J Rehabil Med. 2009;41(9):714-8.

[18] Donker-Cools BHPM, Wind H, Frings-Dresen MHW. Prognostic factors of return to work after traumatic or non-traumatic acquired brain injury. Disability and Rehabilitation. 2015;38(8):733-41. doi: 10.3109/09638288.2015.1061608

[19] van Velzen JM, van Bennekom CAM, Edelaar MJA, Sluiter JK, Frings-Dresen MHW. Prognostic factors of return to work after acquired brain injury: A systematic review. Brain Injury. 2009;23(5):385-95. doi: 10.1080/02699050902838165

[20] Folstein MF, Folstein SE, McHugh PR. Mini-Mental State: A practical method for grading the cognitive state of patients for the clinical. J Psychiatr Res. 1975;12:189-98. 
[21] Stańczak J. MMSE Polska normalizacja. Pracownia Testów Psychologicznych Polskiego Towarzystwa Psychologicznego, Warszawa. 2010.

[22] Yesavage JA, Brink TL, Rose TL, et al. Development and validation of a geriatric depression screening scale: A preliminary report. J Psychiatr Res. 1983;17:37-49.

[23] Albiński R, Kleszczewska-Albińska A, Bedyńska S. Geriatric Depression Scale (GDS). Validity and reliability of different versions of the scale-review. Polish Psychiatry. 2011;XLV(4):55-562.

[24] Juczyński Z. Poczucie skuteczności teoria i pomiar. Acta Universitatis Lodziensis. 2000;4:11-24.

[25] Schwarzer R, Jerusalem M, Juczyński Z. Skala Uogólnionej Własnej Skuteczności GSES In: Juczyński Z. (red), Narzędzia pomiaru w promocji zdrowia i psychologii zdrowia, Warszawa, 2001, pp. 93-97.

[26] Felton BJ, Revenson TA,Hinrichsen, GA. Stress and coping in the explanation of psychological adjustment among chronically ill adults. Soc Sci Med. 1984;18(10):889-98.

[27] Kowalska J, Bojko E, Szczepańska-Gieracha J, et al. Occurrence of Depressive Symptoms Among Older Adults after a Stroke in the Nursing Home Facility. Rehabil Nurs. 2016;41:112-9; doi: 10.1002/rnj.203

[28] Cepuch G, Wordliczek J, Golec A. Wybrane skale do badania natężenia bólu u młodzieży - ocena ich przydatności. Pol Med Paliaty. 2006;5(3):108-13.

[29] Mahoney F, Barthel DW. Functional evaluation: The Barthel Index. Meryland State Medical Journal. 1965;14:61.

[30] Hsueh IP, Lin JH, Jeng JS, et al. Comparison of the psychometric characteristics of the functional independence measure, 5 item Barthel index, and 10 item Barthel index in patients with stroke. J Neurol Neurosurg Psychiatry. 2002;73(2):188-90.

[31] Miller E. Ocena funkcjonalna skuteczności wczesnej rehabilitacji po udarze mózgu - obserwacja półroczna. Przegl Med Uniw Rzeszow. 2007;3:205-10.

[32] Coolen FM, Wade DT, Robb GF, et al. The Rivermead Mobility Index. A further development of the Rivermead Motor Assessment. Int Disabil Stud. 1991;13(2):50-4.

[33] Drużbicki M, Pacześniak-Jost A, Kwolek A. Metody klinometryczne stosowane $\mathrm{w}$ rehabilitacji neurologicznej. PrzeglMed Uniw Rzeszow. 2007;3:268-74.

[34] Black C, Frost D. Health at work: An independent review of sickness absence. London: TSO; 2011.

[35] Coole C, Radford K, Grant M, Terry J. Returning to work after stroke: Perspectives of employer stakeholders, a qualitative study. J Occup Rehabil. 2013;23(3):406-18. doi: 10.1007/s10926-012-9401-1.

[36] Duff N, Ntsiea MV, Mudzi W Factors that influence return to work after stroke. Occupational Health Southern Africa. 2014; 20(3):6-12.

[37] Vestling M, Ramel E, Iwarsson S. Quality of life after stroke: Well-being, life satisfaction, and subjective aspects of work. Scand J Occup Ther. 2005; 12:89-95.

[38] Alaszewski A, Alaszewski H, Potter J, Penhale B. Working after a stroke: Survivors' experiences and perceptions of barriers to and facilitators of the return to paid employment. Disabil Rehabil. 2007;29(24):1858-69. 31.

[39] van der Kemp J, Kruithof WJ, Nijboer TCW, van Bennekom CAM, van Heugten C, Visser-Meily JMA. Return to work after mild-to-moderate stroke: Work satisfaction and predictive factors. Neuropsychol Rehabil. 2017;26:1-16. doi: 10.1080/09602011.2017.1313746

[40] Cordun M, Marinescu GA. Functional rehabilitation strategies for the improvement of balance in patients with hemiplegia after an ischemic stroke. Procedia Social and Behavioral Sciences. 2014;117,19:575-80; doi: 10.1016/j.sbspro.2014.02.265

[41] Muellbacher W, Richards C, Ziemann U, et al. Improving hand function in chronic stroke. Arch Neurol. 2002;59(8):1278-82.

[42] Szczepańska-Gieracha J, Kowalska J, Malicka I, et al. Cognitive impairment, depressive symptoms and the physiotherapy efficacy in elderly people rehabilitated in a nursing home facility. Adv Clin Exp Med. 2010;19(6): 755-64.

[43] Ahn DH, Lee YJ, Jeong JH, et al. The effect of post-stroke depression on rehabilitation outcome and the impact of caregiver type as a factor of post-stroke depression. Ann Rehabil Med. 2015;39(1):74-80; doi: 10.5535/arm.2015.39.1.74

[44] Park GY, Im S, Oh $\mathrm{CH}$, et al. The association between the severity of poststroke depression and clinical outcomes after first-onset stroke in Korean patients. Gen Hosp Psychiatr. 2015;37(3):245-50; doi: 10.1016/j.genhosppsych.2015.02.009

[45] Paolucci S, Braqoni M, Coiro P, et al. Is sex a prognostic factor in stroke rehabilitation? A matched comparison. Stroke. 2006;37:2989-94; doi: 10.1161/01.STR.0000248456.41647.3d

[46] Massucci M, Perdon L, Agosti M, et al. Todeschini E, Franceschini M. Prognostic factors of activity limitation and discharge destination after stroke rehabilitation. Am J Phys Med Rehabil. 2006;85(12):963-70; doi: 10.1097/01.phm.0000242620.44924.1b

[47] Everink IHJ, van Haastregt JCM, van Hoof SJM, et al. Factors influencing home discharge after inpatient rehabilitation of older patients: A systematic review. BMC Geriatrics. 2016;16:5; doi: 10.1186/s12877-016-0187-4

[48] Brauer SG, Bew PG, Kuys SS, et al. Prediction of discharge destination after stroke using the motor assessment scale on admission: A prospective, multisite study. Arch Phys Med Rehabil. 2008;89(6):1061-5; doi: 10.1016/j.apmr.2007.10.042

[49] Tan WS, Heng BH, Chua KS, et al. Factors predicting inpatient rehabilitation length of stay of acute stroke patients in Singapore. Arch Phys Med Rehabil. 2009;90(7):1202-7; doi: 10.1016/j.apmr.2009.01.027

[50] Nuyen J, Spreeuwenberg MP, Groenewegen PP, et al. Impact of preexisting depression on length of stay and discharge destination among patients hospitalized for acute stroke: Linked register-based study. Stroke. 2008;39(1):132-8.

[51] McKenna K, Tooth L, Strong J, et al. Predicting discharge outcomes for stroke patients in Australia. Am J Phys Med Rehabil. 2002;81(1):47-56.

[52] Ohwaki H, Hashimoto $M$, Sato $H$, et al. Gender and family composition related to discharge destination and length of hospital stay after acute stroke. J Exp Med. 2005;207(4):325-32.

[53] Tumasz MT, Trócoli, TT, Fernandes de Oliveira M, et al. Do physically active patients have better functional outcome after stroke? A Systematic Review. J Stroke Cerebrovasc Dis. 2016;25(3):527-32; doi: 10.1016/j.jstrokecerebrovasdis.2015.10.034

[54] Szczepańska-Gieracha J, Kowalska J, Salamon-Krakowska $\mathrm{K}$, et al. Role of family In the process of rehabilitation of elderly hospitalized in a nursing home. Topics in Geriatric Rehabilitation. 2017; doi: 10.1097/TGR.000000000000 147

[55] Szczepańska-Gieracha J, Kowalska J, Pawik M, et al. Evaluation of a short-term group psychotherapy 
used as part of the rehabilitation process in nursing home patients. Disabil Rehabil. 2014;36(12):1027-32; doi: 10.3109/09638288.2013.825331

[56] Amaricai E, Poenaru DV. The post-stroke depression and its impact on functioning in young and adult stroke patients of a rehabilitation unit. J Ment Health. 2016;25(2):137-41; doi: $10.3109 / 09638237.2015 .1022251$
[57] Dušica S-P S, Devečerski GV,Jovićević MN, et al. Stroke rehabilitation: Which factors influence the outcome? Ann Indian Acad Neurol. 2015;18(4):484-7; doi: 10.4103/09722327.165480

[58] Vestiling M, Ramel E, Iwarsson S. Thoughts and experiences from returning to work after stroke. Work. 2013;45(2):201-11; doi: 10.3233/WOR-1215 